\title{
THERMAL DEPENDENCE OF WATER AND ELECTROLYTE EXCRETION IN TWO SPECIES OF LIZARDS*
}

\author{
V. H. SHOEMAKER, $\dagger$ P. LICHT, $\ddagger$ and W. R. DAWSON \\ Department of Zoology, University of Michigan, Ann Arbor, Michigan, U.S.A.
}

(Received 1 May 1967)

\begin{abstract}
Abetract-1. Lizards with different preferred temperatures were water-loaded, and their ability to excrete excess water and conserve electrolytes was tested at several temperatures.

2. Rates of water excretion were much less temperature dependent in lizards having a low preferred temperature, but were maximal at about $30-35^{\circ} \mathrm{C}$ in both species.

3. Urinary sodium levels were minimal at temperatures near the respective preferred temperature of each species.

4. Urinary potassium levels were low and apparently not temperature dependent over most of the range studied, but increased as lethal temperatures were approached.
\end{abstract}

\section{INTRODUCTION}

LIZARDS differ conspicuously in their thermal preferences, and it has been assumed that the differences reflect diversity in the physiological adjustments of these animals to temperature (Dawson \& Bartholomew, 1958). Over the past decade, numerous studies have been devoted to evaluation of this assumption (see Dawson, 1967). It is now possible to correlate the thermal dependence of several physiological processes with the preferred level of body temperature. Despite the interest in this topic and in the water economy and electrolyte excretion of terrestrial vertebrates, effects of temperature on renal function of lizards have not been investigated until very recently. We demonstrated that several aspects of such function are strongly temperature dependent in the skink Tiliqua rugosa (Shoemaker et al., 1966). Information on intraspecific variation in the effects of temperature is obviously needed if meaningful comparisons of renal function are to be made;

* Research was supported in part by grants to W. R. Dawson from the National Science Foundation (G-23137), the Guggenheim Foundation and the Horace H. Rackham School of Graduate Studies, University of Michigan. V. H. Shoemaker and P. Licht held N.S.F. Co-operative Graduate Fellowships during this investigation. The study was conducted using facilities of the Department of Zoology, University of Western Australia, through the courtesy of Professor H. Waring. Dr. A. R. Main of that department contributed in many ways to our studies.

$\dagger$ Present address: Department of Life Sciences, University of California, Riverside, California 92502.

$\ddagger$ Present address: Department of Zoology, University of California, Berkeley, California. 
this is particularly important in view of the fact that other studies of urinary excretion in reptiles have been carried out only at single temperatures on species with imprecisely defined thermal preferences. We have therefore extended the studies of water and electrolyte excretion initiated on T. rugosa to two other species treated in our analyses of the thermal preferences and heat tolerances of Western Australian lizards (Licht et al., 1966a, b). One of these, a gecko, has a significantly lower preferred temperature and more restricted tolerance to heat than $T$. rugosa. The other, an agamid, is more thermophilic than this skink.

\section{MATERIALS AND METHODS}

Lizards used in this study, Phyllurus milii (Gekkonidae) and Amphibolurus barbatus minimus (Agamidae), were captured on Houtman's Abrolhos Islands off the coast of Western Australia. Adult animals of both sexes were used; the twenty representatives of $P$. milii averaging $10.6 \mathrm{~g}$ in weight (range, 6.5-13 g) and the seventeen $A$. barbatus $22 \cdot 2 \mathrm{~g}$ (range, $11-36 \mathrm{~g}$ ). All animals were studied within 3 weeks after capture. They were kept at $25^{\circ} \mathrm{C}$ and provided with water while in captivity, but were not fed, since the presence of feces would have interfered with urine collection.

The ability of lizards to excrete a water load was tested at several temperatures ranging from $14^{\circ}$ to $36^{\circ} \mathrm{C}$ for $P$. milii and from $14^{\circ}$ to $42.5^{\circ} \mathrm{C}$ for $A$. barbatus. The upper temperature used for each species approaches its lethal limit (see Licht et al., 1966b). Most individuals were tested at two temperatures, with at least a week between experiments. Water loads were imposed via a single intraperitoneal injection of $0.1 \mathrm{ml}$ of distilled water per $\mathrm{g}$ of body weight. The animals were held at $20^{\circ} \mathrm{C}$ for $1 \mathrm{hr}$ following the injection of water to ensure osmotic equilibration before the tests were begun. One hour had previously been found sufficient for equilibration in a large skink, as indicated by stabilization of the concentration of sodium in the plasma (Shoemaker et al., 1966). At the end of the equilibration period, any accumulated urine was expressed from the cloaca and each animal was weighed to the nearest $0.01 \mathrm{~g}$ on a Mettler balance of appropriate sensitivity. (Urine produced during the equilibration period was less than 5 per cent of the injected volume.) In tests involving $A$. barbatus, the cloaca was then sealed by wrapping a strip of masking tape around the base of the tail and the animal was weighed again. Each of these agamids was then placed in a separate container within a thermostatically controlled chamber. After $3 \mathrm{hr}$, it was weighed with the tape in place. Then the tape was removed and a sample of the accumulated urine was collected by inserting a fire-polished glass capillary into the cloaca. Any remaining urine was expressed and blotted, and the animal was weighed again. Urine production over the $3-\mathrm{hr}$ period was determined from the loss of weight associated with the removal of the urine. The weighing and sampling procedure was repeated in the subsequent 3-hr period so that rates of urine production and urinary $\mathrm{Na}^{+}$and $\mathrm{K}^{+}$concentrations were obtained for a total of $6 \mathrm{hr}$ following equilibration of the water load.

A slightly different procedure was used for $P$. milii, because repeated taping of the cloaca caused these animals to cast their tails. We therefore omitted the taping 
procedure in water-loaded geckos, but included several taped controls in each run. The weight losses of these controls over the 6-hr period agreed with the weight losses of the experimental animals during the two 3-hr intervals between weighings. This demonstrated that the water-loaded lizards did not void urine during these periods, even though their cloacas were not sealed.

High humidities were maintained in the constant-temperature chambers to minimize pulmocutaneous water losses. Total non-urinary weight loss over the 6-hr period never exceeded 5 per cent of the water load. Urine samples were sealed in Pyrex capillaries and analyzed within a few days for sodium and potassium using a Coleman flame photometer (model 21).

\section{RESULTS}

The gecko and the agamid differed markedly in the rate at which they excreted excess water (see Table 1). At each temperature where data were obtained for both species $\left(14^{\circ}, 21^{\circ}, 31^{\circ}, 36-37^{\circ} \mathrm{C}\right), P$. milii produced urine at a significantly higher

TABLE 1-URINE PRODUCTION IN WATER-LOADED LIZARDS AT VARIOUS TEMPERATURES

\begin{tabular}{|c|c|c|c|c|}
\hline \multirow{2}{*}{$\begin{array}{l}\text { Temperature } \\
\left({ }^{\circ} \mathrm{C}\right)\end{array}$} & \multirow[b]{2}{*}{$\mathbf{N}$} & \multicolumn{2}{|c|}{ Urine production $\mathrm{ml} / 100 \mathrm{~g} *$} & \multirow{2}{*}{$\begin{array}{c}\% \text { of load } \\
\text { excreted in } \\
6 \mathrm{hr}\end{array}$} \\
\hline & & $0-3 \mathrm{hr}$ & $3-6 \mathrm{hr}$ & \\
\hline \multicolumn{5}{|c|}{ Phyllurus milii } \\
\hline 14 & $\mathbf{5}$ & $1 \cdot 28 \dagger(0 \cdot 6-1 \cdot 7)_{\ddagger}^{\dagger}$ & $1 \cdot 59(1 \cdot 0-2 \cdot 3)$ & $28 \cdot 7$ \\
\hline 21 & 7 & $2 \cdot 28 \quad(1 \cdot 3-3 \cdot 2)$ & $1.92(1.1-2.8)$ & $42 \cdot 0$ \\
\hline 26 & 9 & $2.88 \quad(1.7-4.9)$ & $2 \cdot 10(1 \cdot 4-4 \cdot 3)$ & $49 \cdot 8$ \\
\hline 31 & 5 & $4.26 \quad(2.4-6.8)$ & $2.52(1.1-3.4)$ & $67 \cdot 8$ \\
\hline 36 & 7 & $3 \cdot 86 \quad(2 \cdot 7-6 \cdot 6)$ & $2 \cdot 52(1 \cdot 6-5 \cdot 2)$ & $62 \cdot 7$ \\
\hline \multicolumn{5}{|c|}{ Amphibolurus barbatus } \\
\hline 14 & 4 & $0.31(0 \cdot 17-0 \cdot 40)$ & $0.36(0.17-0.69)$ & 6.7 \\
\hline 21 & 4 & $0.82(0.40-1.0)$ & $0.83(0.33-1.4)$ & $16 \cdot 5$ \\
\hline 31 & 9 & $1.78(0.54-3.7)$ & $1.74(0.71-2 \cdot 8)$ & $35 \cdot 2$ \\
\hline 37 & 7 & $1 \cdot 76(0 \cdot 66-3 \cdot 7)$ & $1 \cdot 51(0 \cdot 73-2 \cdot 2)$ & $32 \cdot 7$ \\
\hline $42 \cdot 5$ & 5 & $0.97(0.69-1.4)$ & $0 \cdot 81(0 \cdot 42-1 \cdot 3)$ & $17 \cdot 8$ \\
\hline
\end{tabular}

* Total urine produced in each of the two $3-\mathrm{hr}$ collecting periods.

$\dagger$ Mean. $\quad \ddagger$ Range.

rate on a weight-specific basis $(P<0.05)$ than did $A$. barbatus. In fact, the lowest rates observed for the gecko, those at $14^{\circ} \mathrm{C}$, were comparable to the highest rates for the agamid which occurred between $31^{\circ}$ and $40^{\circ} \mathrm{C}$. A. barbatus excreted no more than a third of the water load in $6 \mathrm{hr}$ in this thermal range, and rates of urine production were fairly uniform over this period. The gecko excreted a greater fraction of the load, about two-thirds at $31^{\circ}$ and $36^{\circ} \mathrm{C}$, and in this species rates of urine production tended to decline in the second 3-hr period. Interspecific differences in the thermal dependence of urine production are evident when rates 
of production are plotted semi-logarithmically as a function of temperature (Fig. 1). Urine production doubled between $15^{\circ}$ and $30^{\circ} \mathrm{C}$ in $P$. milii and increased fivefold over the same range of temperatures in $A$. barbatus. Between $30^{\circ}$ and $35^{\circ} \mathrm{C}$ rates

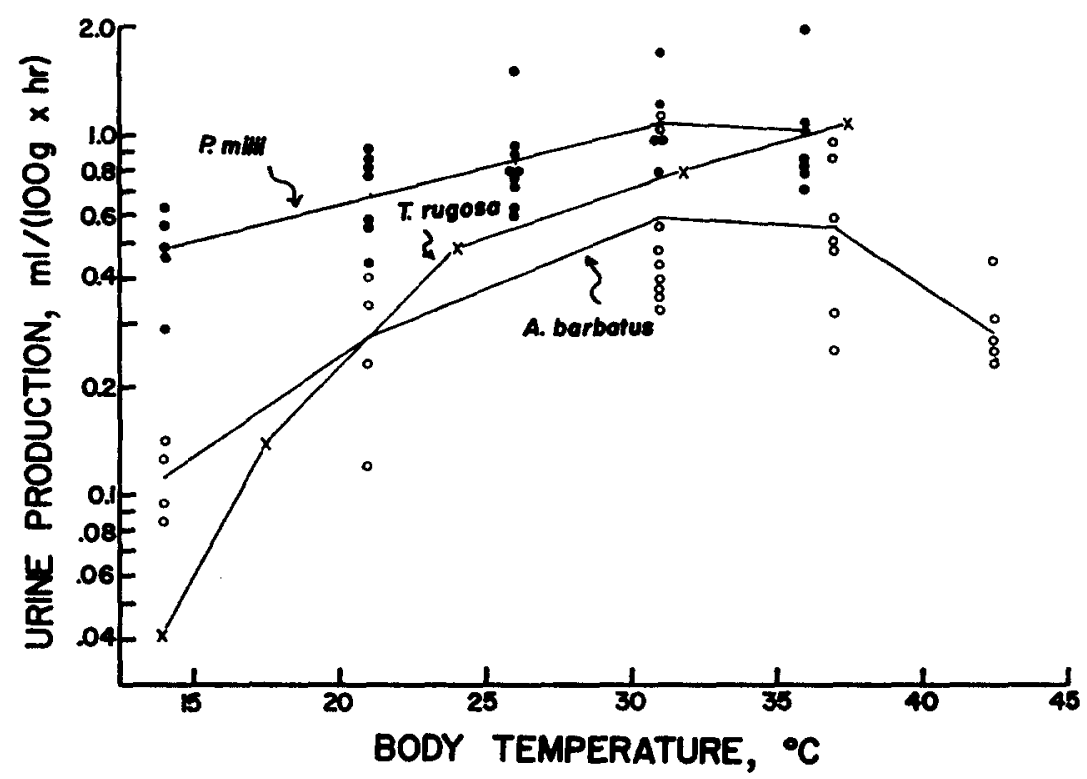

FIG. 1. Effect of temperature on rate of urine production in water-loaded lizards; Phyllurus milii ( ), Amphibolurus barbatus ( $O$ ), and Tiliqua rugosa $(\times)$. All rates are based on $6 \mathrm{hr}$ of urine collection. Individual values are shown for $P$. milii and A. barbatus. Average values for T. rugosa from Shoemaker et. al. (1966) are included for comparison (semi-logarithmic plot).

of urine production leveled off in both species and, in $A$. barbatus, declined slightly at $42.5^{\circ} \mathrm{C}$. These trends may also be seen by examining the temperature coefficients $\left(Q_{10}\right.$ 's) shown in Table 2 . These coefficients were determined graphically from Fig. 1 and are thus based on rates for the entire 6-hr period. Nearly identical values are obtained if only the first 3 -hr period is considered.

TABle 2 - Temperature COEFFICIENTS $\left(Q_{10}\right.$ 's) FOR RATE OF URINE PRODUCTION IN WATERLOADED LIZARDS*

\begin{tabular}{lrccc}
\hline & \multicolumn{4}{c}{ Temperature range $\left({ }^{\circ} \mathrm{C}\right)$} \\
\cline { 2 - 5 } \multicolumn{1}{c}{ Species } & $15-20$ & $20-25$ & $25-30$ & $30-35$ \\
\hline Phyllurus milli & $1 \cdot 6$ & $1 \cdot 6$ & $1 \cdot 6$ & $0 \cdot 9$ \\
Amphibolurus barbatus & 3.6 & $2 \cdot 5$ & $2 \cdot 3$ & $1 \cdot 0$ \\
Tiliqua rugosa $\dagger$ & 14.5 & $5 \cdot 1$ & 1.9 & 1.8 \\
\hline
\end{tabular}

* Based on semi-logarithmic plot of average rates over $6 \mathrm{hr}$.

† From data of Shoemaker et al. (1966). 
Temperature also had a marked influence on the ability of water-loaded lizards of both species to conserve sodium while excreting excess water. Urinary sodium levels were highest at $14^{\circ} \mathrm{C}$, declining as temperature increased to some intermediate value characteristic of the species, and finally increasing somewhat at the highest temperatures investigated (Fig. 2). Urine of $\boldsymbol{P}$. milii was considerably more

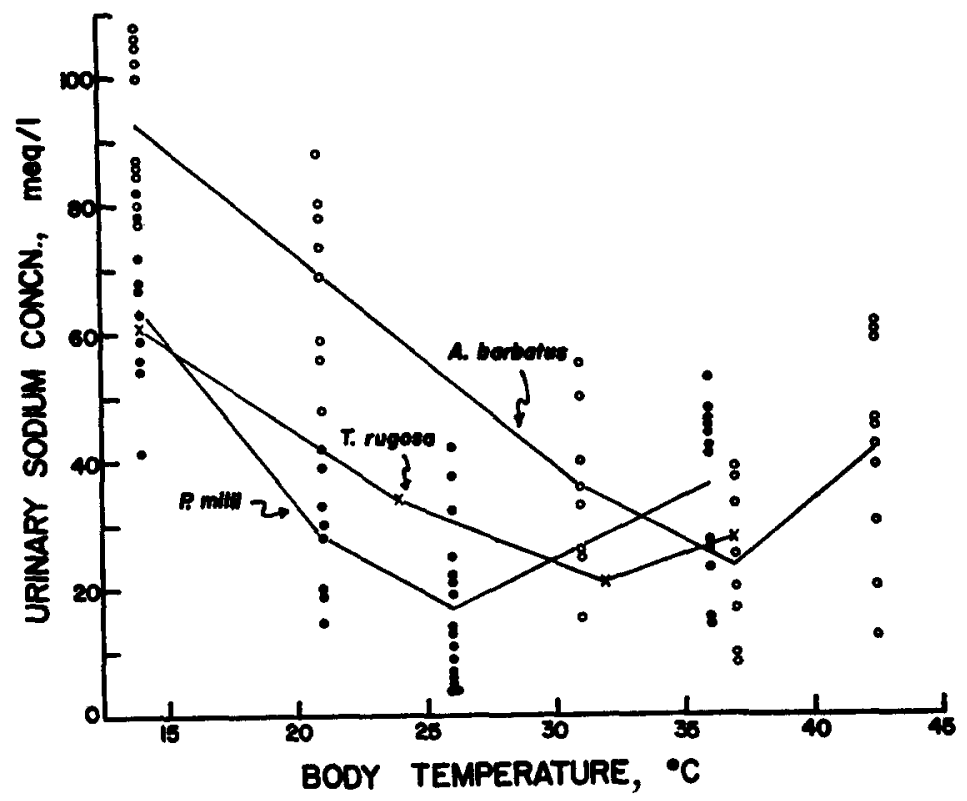

FIG. 2. Effect of temperature on urinary sodium concentration in water-loaded lizards; $P$. milii (O), A. barbatus (O), and $T$. rugosa (x). Concentrations of both samples collected from each lizard during the 6-hr period are shown for $P$. milii and $A$. barbatus. Values for $T$. rugosa (Shoemaker et al., 1966) are comparable averages.

dilute than that of $A$. barbatus below $25^{\circ} \mathrm{C}$. The lowest mean urinary sodium level observed for $P$. milii (17 mequiv. $/ \mathrm{l})$ was that at $26^{\circ} \mathrm{C}$, whereas the corresponding minimum for $A$. barbatus ( 23 mequiv. $/ 1)$ was seen at $37^{\circ} \mathrm{C}$.

Concentrations of potassium in the urine of water-loaded lizards varied little with body temperature over most of the range studied, but some elevation of urinary potassium levels was apparent at the highest temperature tested for each species. Between $14^{\circ}$ and $26^{\circ} \mathrm{C}$, urine of $P$. milii averaged 11 mequiv. $\mathrm{K}+/ 1$ (range, 6-26 mequiv./l), whereas urine produced by these lizards at $36^{\circ} \mathrm{C}$ averaged 30 mequiv. $K^{+} / 1$ (range, 7-58 mequiv, $/ 1$ ). At temperatures between $14^{\circ}$ and $37^{\circ} \mathrm{C}$ urinary potassium concentrations for $A$. barbatus averaged 22 mequiv./l (range, $10-44$ mequiv. $/ 1$ ); at $42 \cdot 5^{\circ} \mathrm{C}$ they averaged 46 mequiv./1 (range, 26-73 mequiv./1).

At the end of the study, six $P$. milii and eleven $A$. barbatus were sacrificed. 
Both kidneys were removed from each lizard and weighed together to the nearest $\mathrm{mg}$. In the gecko the mean fresh weight of the paired kidneys was $6.4 \mathrm{mg} / \mathrm{g}$ body wt. (S.E. $=0.038$ ) compared to $3.2 \mathrm{mg} / \mathrm{g}$ body wt. (S.E. $=0.025$ ) in the agamid.

\section{DISCUSSION}

The mean preferred temperature (i.e. mean body temperature maintained in a thermal gradient) of $P$. milii is quite low compared to that of $A$. barbatus (see Licht et al., 1966a). The former remained at the cool end of a gradient in which $25^{\circ} \mathrm{C}$ was the lowest temperature available, and their body temperature averaged $21 \cdot 6^{\circ} \mathrm{C}$ in a gradient with a range of $15^{\circ}-35^{\circ} \mathrm{C}$. A barbatus, on the other hand, maintained body temperatures between $33^{\circ}$ and $39^{\circ} \mathrm{C}$ with a mean preferred temperature of $36 \cdot 3^{\circ} \mathrm{C}$. Representatives of the two species also differ in heat resistance. P. milii survived less than $1 \mathrm{hr}$ at $40 \cdot 5^{\circ} \mathrm{C}$ and suffered high mortality following a 3-hr exposure to $37 \cdot 5^{\circ} \mathrm{C}$, whereas $A$. barbatus readily survived $3 \mathrm{hr}$ at $43.5^{\circ} \mathrm{C}$ (Licht et al., 1966b). Field observations reflect even greater differences in the thermal relations of these species. The gecko is nocturnal and may be found foraging at temperatures below $20^{\circ} \mathrm{C}$, whereas the agamid is diurnal and, when active in the field, maintains temperatures near those observed in the laboratory thermal gradient.

Although there was no obvious difference in the body temperature at which maximal rates of water excretion were achieved by the two species, the gecko is less temperature sensitive and has a far greater capacity for water excretion at low temperatures. This difference in renal function is consistent with the tendency of the gecko to be active over a lower and wider range of body temperatures. Temperature dependence of water excretion in the skink $T$. rugosa is even greater than that of the agamid (Fig. 1, Table 2). The skink resembles the agamid in that it maintains a relatively constant body temperature in the field and in laboratory thermal gradients. The mean preferred temperature of the skink $\left(33.8^{\circ} \mathrm{C}\right)$ greatly exceeds that of the gecko and is slightly lower than that of $A$. barbatus (Licht et al., 1966a).

We have examined the effect of temperature on renal function in $T$. rugosa in somewhat greater detail (Shoemaker et al., 1966). Water-loaded lizards of this species at $37^{\circ} \mathrm{C}$ excreted twenty-five times more water during the first $6 \mathrm{hr}$ than they did at $14^{\circ} \mathrm{C}$, and there was a corresponding twenty-fivefold increase in glomerular filtration rate. This suggests that interspecific differences in the thermal dependence of water excretion reflect differences in the thermal dependence of factors (e.g. arterial pressure) that influence rates of glomerular filtration. For example, in the iguanid lizard Sauromalus obesus, arterial pressure increases between $5^{\circ}$ and $25^{\circ} \mathrm{C}$ with a $Q_{10}$ of 2.4 and is essentially independent of temperature between $25^{\circ}$ and $45^{\circ} \mathrm{C}$ (Templeton, 1964).

The highest rates of urine production attained by $P$. milii were considerably greater than those of $A$. barbatus, and this may be a reflection of the larger weightrelative size of the kidneys in the gecko. Roberts \& Schmidt-Nielsen (1966) 
compared renal responses of another gecko (Hemidactylus) and two iguanids (Phrynosoma and Tropidurus) to water loading, salt loading and dehydration at about $25^{\circ} \mathrm{C}$. The gecko excreted excess water at a rate similar to that observed for $P$. milii at a comparable temperature, and, like the agamid studied here, the iguanids produced urine at a much lower rate. More detailed comparison would be of little value because of differences in the methods of water-loading and urine collection in the two studies. Also, interspecific differences in renal function found by Roberts and Schmidt-Nielsen are probably influenced to some extent by the fact that the temperature employed does not bear the same relation to the preferred level in all three species.

Analysis of the effects of temperature on the ability of lizards to produce urine dilute in sodium is complicated by concomitant changes in the rate of urine flow. However, diuretic water-loaded reptiles appear to resorb a fairly uniform fraction of the filtered water (40-60 per cent) as indicated by studies on water snakes (LeBrie \& Sutherland, 1962) and several species of lizards (Roberts \& SchmidtNielsen, 1966; Shoemaker et al., 1966). Moreover, this fraction is independent of temperature in $T$. rugosa (Shoemaker et al., 1966). It therefore seems reasonable to assume that the temperature at which urinary sodium levels are minimal are those at which the greatest fraction of this solute is resorbed. Although the temperatures employed in this study were too widely spaced to permit precise determination of this temperature, it is clear from Fig. 2 that it is considerably lower in $P$. milii than in $A$. barbatus. In general, lizards appear best able to conserve sodium while excreting excess water when kept at temperatures near their preferred levels, and the gecko was particularly effective in that it excreted the greatest amount of urine at the lowest sodium concentration. In $T$. rugosa, minimal urinary sodium levels were observed at an intermediate temperature (see Fig. 2) corresponding to the intermediate position of its thermal preferendum. The elevation of urinary sodium and potassium levels noted at the highest temperatures examined may reflect impairment of ion transport mechanisms, since these temperatures approach lethal levels.

It is not known whether dilution of the urine with respect to sodium is accomplished by the distal tubules, the cloaca, or both. Data of Roberts \& SchmidtNielsen (1966) are of interest in this connexion. They collected urine directly from the ureters of water-loaded lizards and observed urinary sodium levels near that of the plasma in contrast to the much lower values reported here. They found urine of the gecko Hemidactylus to be somewhat more dilute with respect to sodium (98 mequiv./1) than that of the iguanids Phrynosoma (119 mequiv./1) and Tropidurus (124 mequiv. $/ 1)$ at about $25^{\circ} \mathrm{C}$. Ureteral urine of water-loaded snakes (Natrix) at $26^{\circ} \mathrm{C}$ contains about 40 mequiv. $\mathrm{Na}^{+}$and 10 mequiv. $\mathrm{K}+/ 1$ (LeBrie $\&$ Sutherland, 1962), and these values approximate concentrations of cloacal urine of the lizards used in this study. The extent to which cloacal resorption accounts for the differences in urine composition of the lizards compared here awaits further investigation. Junqueira et al.'s (1966) analysis of the resorptive function of the cloaca in snakes of several genera should give additional impetus for similar studies in lacertelians. 
Whatever the role of the cloaca in the total response may be, it is evident that capacities of lizards for excretion of water and resorption of sodium show interspecific differences in thermal dependence that can be correlated with their characteristic body temperatures during activity.

\section{REFERENCES}

Dawson W. R. (1967) Interspecific variation in physiological responses of lizards to temperature. In Symposium on Lizard Ecology (Edited by MiLSTEAd W.), pp. 230-257. University of Missouri Press, Columbia.

Dawson W. R. \& BARTHolomew G. A. (1958) Metabolic and cardiac responses to temperature in the lizard Dipsosaurus dorsalis. Physiol. Zool. 31, 100-111.

Junqueira L. C. U., Malnic G. \& Monge C. (1966) Resorptive function of the ophidian cloaca and large intestine. Physiol. Zool. 39, 151-159.

LeBrie S. J. \& Sutherland I. D. W. (1962) Renal function in water snakes. Am. F. Physiol. 203, 995-1000.

Licht P., Dawson W. R., Shoemaker V. H. \& Main A. R. (1966a) Observations on the thermal relations of Western Australian lizards. Copeia 1966, 97-110.

Licht P., Dawson W. R. \& Shoemaker V. H. (1966b) Heat resistance of some Australian lizards. Copeia 1966, 162-169.

RoBERTS J. S. \& SCHMIDT-NIELSEN B. (1966) Renal ultrastructure and excretion of salt and water by three terrestrial lizards. Am. F. Physiol. 211, 476-486.

Shoemaker V. H., LichT P. \& Dawson W. R. (1966) Effects of temperature on kidney function in the lizard Tiliqua rugosa. Physiol. Zool. 39, 244-252.

TEMPLETON J. R. (1964) Cardiovascular response to temperature in the lizard Sauromalus obesus. Physiol. Zool. 37, 300-306. 